\title{
Development of Quality Control and Breeding Management System of Goats Based on Information and Communication Technology
}

\author{
Teppei HIRATA, Ai IJICHI, Miwako OSHIRO, Chiaki GAKIYA, Ken KUWAE, Akimichi \\ SHIMABUKURO, Shiro TAMAKI \\ College of Information Engineering, University of the Ryukyus, \\ 1 Senbaru, Nishihara town, Okinawa, 903-0213,JAPAN, \\ teppei@neo.ie.u-ryukyu.ac.jp
}

\begin{abstract}
In the context of the occurrence of infectious diseases in livestock and the increasing demand for animal products in the Asian region, it is necessary to establish information management systems for animal production and prevention of epidemics. In this study, we propose a next-generation information management system of animal production that utilizes information and communication technology such as RFID, cloud systems, and mobile communication network. Also, we conducted operational test of the information system by using goat as a model for the target animal in order to evaluate the requirements for the dissemination of the system and the remaining issues.
\end{abstract}

Keywords: Animal production, RFID, Cloud system, Goat, ICT

\section{Introduction}

With both the background of the recent year's occurrence of foot and mouth disease (FMD) and BSE, and the increasing demand for livestock products in the Asian region, it is necessary to establish an information management system for animal production and prevention of epidemics. Since the outbreak of BSE, Asian countries mainly promote the implementation of ear tag for its livestock traceability systems as an indicator of identification of the individual animals. These systems focus on BSE, and also focus on the movement management of cattle. With the background of these in mind, the information management system which manages information on animal production and prevention of epidemics is in great demand.

The systems, established after the occurrence of BSE in Asian region, only focus on how to control the infection of BSE and the systems primarily focus on cows as its target animals.

Australia and Canada are using RFID for the identification of cows. In case of Australia, the systems adopt the method of placing the capsulated RFID in cows' stomachs.

Assuming the movement of livestock in the region, the livestock passport system has been introduced in the EU. The examples of the attributes the system manages include the coat colour, breed information, etc. and these attributes are tied to the identification number of the ear tag of the animals.
National Livestock Identification Scheme (NLIS) is a cattle traceability system in Australia. This scheme was made mandatory in 2005. The development of NLIS is based on Property Identification Code (PIC). The systems' characteristics include the utilization of an electronic label as an identifier for animal identification. The label is composed from the capsule in the rumen and ear tag with an embedded microchip.

The implementation of the traceability system for each nation is strictly regulated and enforced by the national law. The system regulation is designed specifically for the management of the movement of livestock. However, the consumers in EU demand the disclosure of the information not only on the movement of animals, but also on the feeding (diet and medication of animals.)

The effort for the disclosure of the correct information on the animal production in associated with the NLIS to consumers has been made in Australia. This project is called the FARMA project [1]. FARMA project is intended to manage the information (i.e. feeding, veterinary medicine, etc.) collectively. The FARMA project is advanced, leading ICT project in agricultural sector.

In Asian countries, in particular in Southeast Asia, the demand for animal products is increasing due to its population growth and its economical development. Nevertheless, the development of a traceability system to sustain the safety of animal products is insufficient in these regions. In fact, the media reported the 
occurrence of epidemics of FMD in South Korea. In order to prevent such epidemics, the importance of quarantine in the border is increasing. Also, it is necessary to establish the animal quarantine system that covers the entire Asian region.

It is also expected that logistics of animal and food in Asia will be increase, due to the realization of the Asian Highway vision. In the near future, it is expected that the volume of the imports and the consumption of agricultural products in the Asian region will increase drastically. Instead of the projection stated above, the implementation of traceability systems in Asian region is not matured yet. The reason of immaturity might include cultural and religious factors.

The following two objectives are the purposes of study.

1. To propose the next generation information management system for animal production, tailored for Asian region.

2. To argue the requirement of new system, building to test for dairy goat farmers.

\section{Proposal of Next Generation System for Animal Production}

\subsection{Overall design of the system}

In Asian region, unlike North America, Australia or Europe, there are many small-scale livestock farmers which spread throughout the wide area, and there are relatively small numbers of large-scale farmers which play a central role of the area. Therefore, it is difficult to adopt the existing traceability systems in the Asian region. It is necessary to come up with new approach to develop the traceability systems for Asian region. The approach that we have conceived is to produce the secondary information with the new value to analyze diversified animal production information. This secondary information is beneficial for the development of veterinarian drags and animal feed. It is considered that the users of the data are borne to the cost of developing the database systems. The potential users of the systems will include, but not limited to, distribution trading company, a pharmaceutical and feed manufacturing companies. We consider the business model of the traceability systems is very important because it has great impact in dissemination of the systems to small-scale farmers which tends to run in relatively small and limited annual budget. The usage of the systems by the farmers is directly related to the sustainability of the safe production of animal products. We think the key to diffuse the implementation of the systems for the farmers resides in how we structure the business plan to make the implementation beneficial for the small farmers. Also it is very important as to how we will be able to increase the farmers' awareness of the sustainability of food safety in Asian region.

In this system, all the stakeholders in the livestock industry can input and output the related information to common database. The stakeholders include producers (farmers), veterinarians, restaurants, government officials, and animal science researchers (Figure.1.).

In the systems, all the animals have unique ID numbers for its identification, and each animal is labeled by ear tags, in which the embedded RFID is installed. Furthermore, the database is stored on the cloud-based system, so that all the information will be entered or retrieved through the internet. In addition, the system was designed in the way that the producers and veterinarians carry out input and output of information by using the mobile terminals.

This system consists of the mobile terminal for veterinarians and producers to use sensor node (sensor to collect information automatically) and cloud server (with the ability to analyze the information and store the information). There is a group of dedicated application interface (API.) (Figure. 2).

\section{Development of Information- Collection System for Dairy Goat Farmers}

\subsection{Overview of the system}

With the aim of revealing the potential problem of the information management systems for animal production, we developed the system that automatically collects information for dairy production of goat. The system was developed and tested in the real local farmer.

The reason of using goat as a model livestock is because it has gentle characteristics. The characteristics of goat are totally different from those of pigs (i.e. pigs bite ears with each 


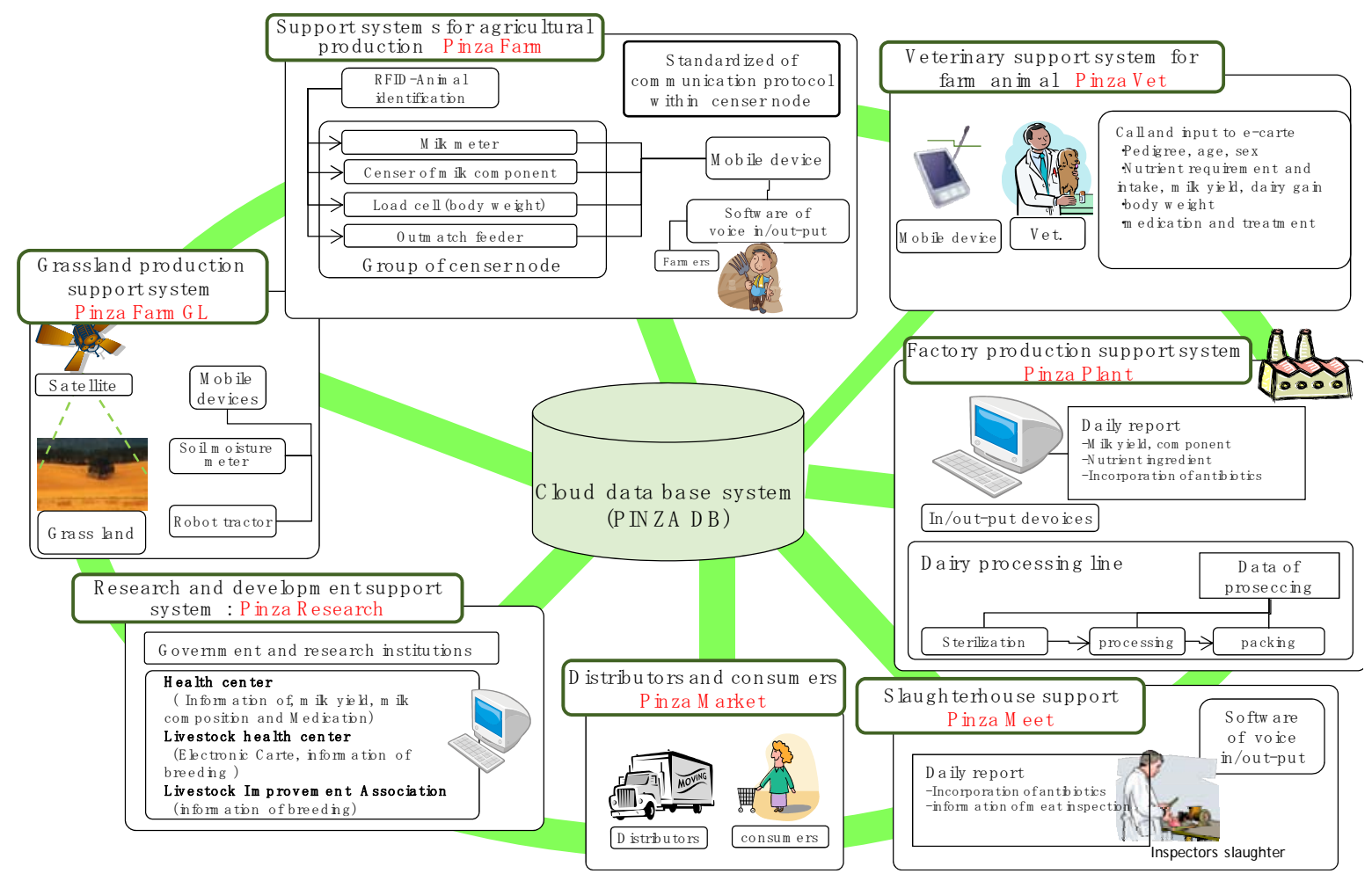

Figure 1. Livestock production information management system

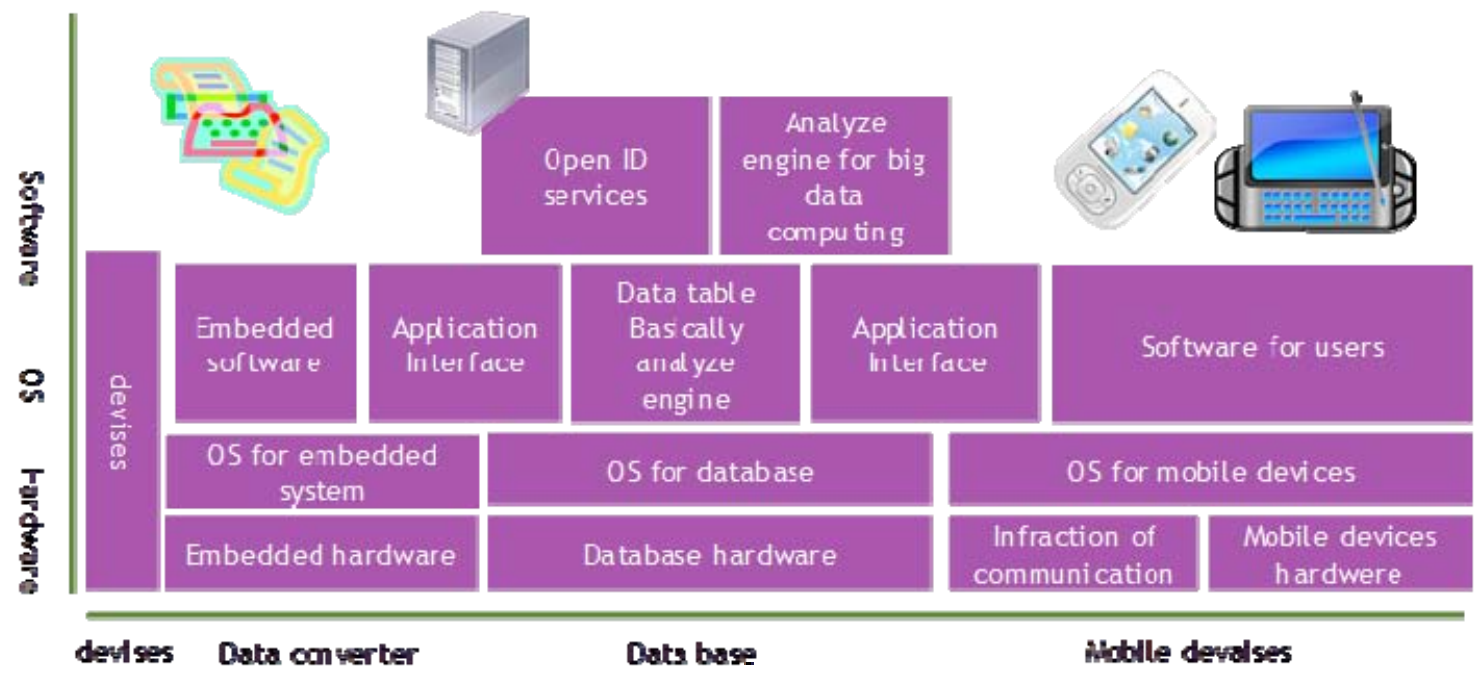

Figure 2. Architecture of the mobile computing

other.) and goat is used of a wide variety of animal products for its milk, meat, and the hair.

\subsection{Specifications of the system}

In this system, the body weight and milk yield of individual animal was recorded. The information was sent to the cloud server, which is physically located at the facilities in the University of the Ryukyus. 3G network connection was used for the communication between the cloud server and the digital sensors in the farm. In addition, we investigated the functionality for breeding improvement of goat by using the collected information. In addition, it is also considered that the ability of breeding calculation based on the data collected by the system.

\subsection{Configuration of the system}

The configuration of this system is described below. The load cell was used as a sensor to measure milk yield and body weight of goats. 
In case of measuring the amount of milk, the load cell was placed under the bucket milker. The change in weight was recorded as the amount of milk yield. The signals from the load cell were amplified by the circuit and normalized. The amplified signals were recorded by a dedicated data logger system. Data logger has a function that works with the mobile terminal. For the connection between mobile devices and data logger, USB connection was used.

In recent years, progress of mobile phone especially smartphone is remarkable, and it has also been the recent development of various types of sensor networks using smartphone[2]. Therefore, smartphone has been introduced as a data hub on the farm. This has been realized construction of an inexpensive system.

In this study, Mobile phone SC-04D, manufactured by Samsung equipped with Android 4.1, was used. In addition, RFID reader RT100 (Real Trace Co. Ltd.) to read the individual number of goats was used.

Individual identification number, which was read by the RFID reader, was sent to the mobile terminal through the Bluetooth connection.
System configuration is schematically presented in Figure 3.

\section{4 Workflow of the system}

Work flow of the system is described below. In case of measuring of goat milk, the data is stored by the following procedure.

- STEP1 The operator starts the software that has been pre-installed on the mobile device and the communication in between data logger and the RFID reader is established.

- STEP2 Individual identification number is sent to the mobile terminal when the workers read milking animals' ear tags by the RFID reader. At the same time, the transmission of ID number is triggered to start the system's recording process. At this point, the weight of the bucket milker is recorded as its initial value, and the increase of the weight at the end point of the measurement is recorded as the weight of the milk yield.

- STEP3 The worker scans the ear tag again when milking process is completed. The software creates the data table that

\section{Dairy farming support system Antenna RFID}

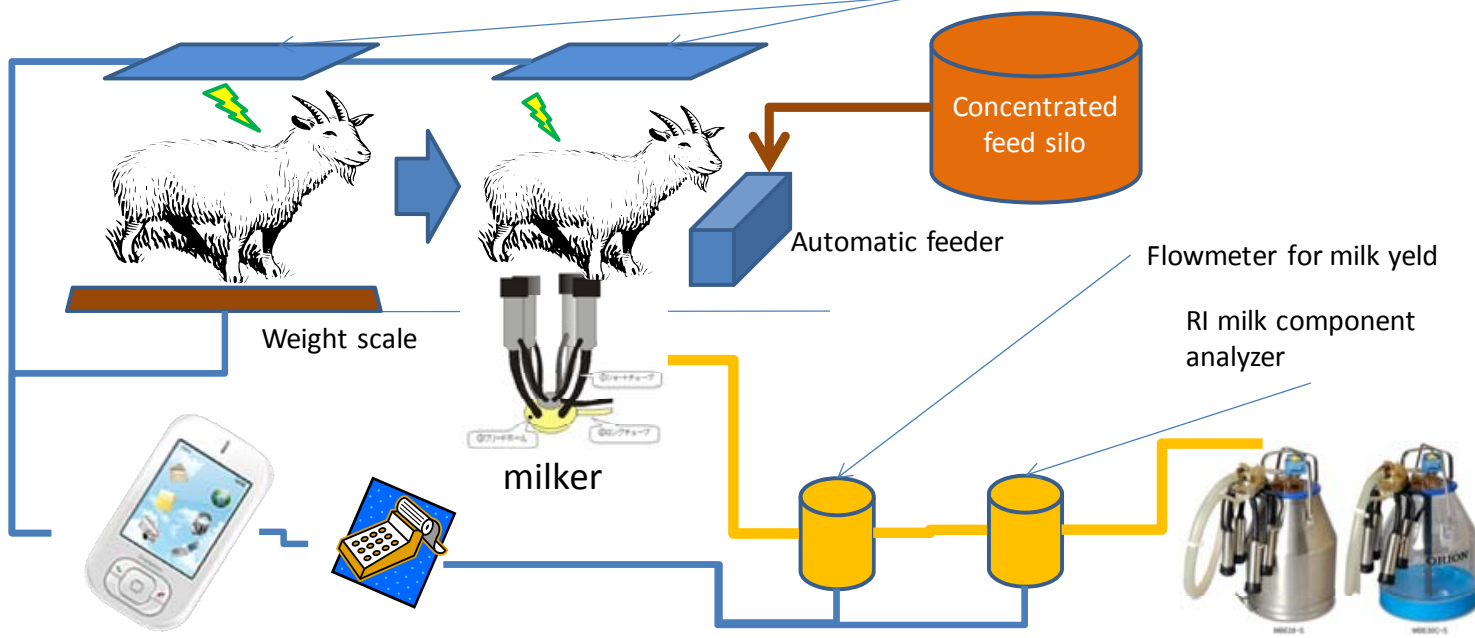

Use of information and devices

Bucket milker

\begin{tabular}{|c|c|c|}
\hline Devices & Data & Use of information \\
\hline Weight scale & Weight changes of individual animal & \multirow{3}{*}{$\begin{array}{l}\text { Daily gain, management of milk yield, Calculation of } \\
\text { nutritional requirements, The matching of amount of } \\
\text { feed and nutrition } \\
\text { required }\end{array}$} \\
\hline Flow meter for milk yield & Milk yield of individual animal & \\
\hline RI milk component analyzer & Milk component of individual animal & \\
\hline Automatic feeder & $\begin{array}{l}\text { The amount of concentrated feed } \\
\text { feeding }\end{array}$ & $\begin{array}{l}\text { Automatic feeding of concentrate meets the design of } \\
\text { nutrition }\end{array}$ \\
\hline
\end{tabular}

Figure 3. Information collection system for goat milking farmar 
integrates information, such as individual identification number, milk yield, and the time that has been spent on entire milking process. Then the data was sent to the cloud server through the $3 \mathrm{G}$ network.

In the measurement of individual body weight of the goat, the same procedure, as described above, is used.

\subsection{Milk yield prediction system}

It is known that milk yield of dairy livestock, such as cattle and goats, increases rapidly until 30 days after delivery, and then the yield is decrease slowly. This gamma curve is known as Wood curve [3]. Wood (1967) has proposed a mathematical model representing a lactation curve of dairy cows.

Thereafter, this mathematical model is used to represent lactation curve in various breeding of milking animal including goat. In Wood model, lactation curve is represented by only three parameters. In addition, it is able to estimate that important variable such as the amount of a maximum milk production and milk yield in total lactation term. For this reason, it is widely used for breeding and improvement management of dairy cattle and goat [4]. This is also applied in the goat farming [5].

In this study, the development of prediction system of milk yields in goat was examined by using Wood model. This system is predicted using the data collected automatically. The lactation curve can be represented by the following equation.

$y_{t}=a t^{b} e^{-c t}$

As stated above, $\mathrm{y}_{\mathrm{t}}$ is milk yield, and $\mathrm{t}$ is the number of weeks after delivery.

The constant a, b, and c have the meanings as indicated in Table 1.
Initially, the algorithm for prediction by Linear Least Squares Method is examined. The following equation was obtained that take the natural logarithm of equation (1).

$$
\log y=\log a+b \log t-c t \text {. }
$$

The following equation (3) was obtained that took place in the equation (2), as $\mathrm{Y}=\log \mathrm{y}$, $\mathrm{A}=\log \mathrm{a}, \mathrm{T}=\log \mathrm{t}$.

$Y=A+b T-c t$.

Linear Least Squares Method was applied to equation (3).

$J=\sum\{Y-(A+b T-c t)\}^{2}$.

Constant a, b, c are (was) determined to minimize $\mathrm{J}$ in equation (4).

And the derivation of the various parameters using the Wood model was described below. Following equation (5) was obtained, differentiating equation (1) with the variable $t$, the number of weeks after delivery.

$d y / d t=a t^{b-1} e^{-c t}(b-c t)$.

The equation (5) shows the peak of lactation. The maximum milk yield $\mathrm{y}_{\max }$ is obtained, substituting the $t_{\max }$ in equation (1).

$y_{t}=a(b / c)^{b} e^{-b}$.

In addition, the persistence coefficients indicating the ability to maintain a certain amount of milk production are determined in the following equation (7).

$s=-(b+1) \log c$.

The sum of milk yield up to 240 days after delivery is often used as an indicator to compare the total annual milk yield per lactation. The lactation period is different for individual animal. 240 days milk yield $\mathrm{TM}_{240}$ was derived as follows.

Table 1. Definition of constant a, b, c in Wood model

\begin{tabular}{l}
\hline a \\
b $\begin{array}{l}\text { The extent of the increasing of milk yield after delivery to the } \\
\text { top of peak of lactation }\end{array}$ \\
c \\
The extent of the reduction in the amount of milk after the peak \\
\hline \hline
\end{tabular}




$$
T M_{240}=\sum_{n=1}^{240}\left\{a(n / 7)^{b} e^{-c(n / 7)}\right\} .
$$

This algorithm was described by the language $\mathrm{C}^{++}$, and the program was developed and implemented in the system. In order to demonstrate the execution of program, the program was evaluated. In order to evaluate the program, the data of standard milk yield for various breeding of goat was obtained from the website of the United States Department of Agriculture [6]. The number of individual data is 61 .

Figure 4 shows that the graph depending on the result calculated by the program. The data used for this graph is related Nubian breed.

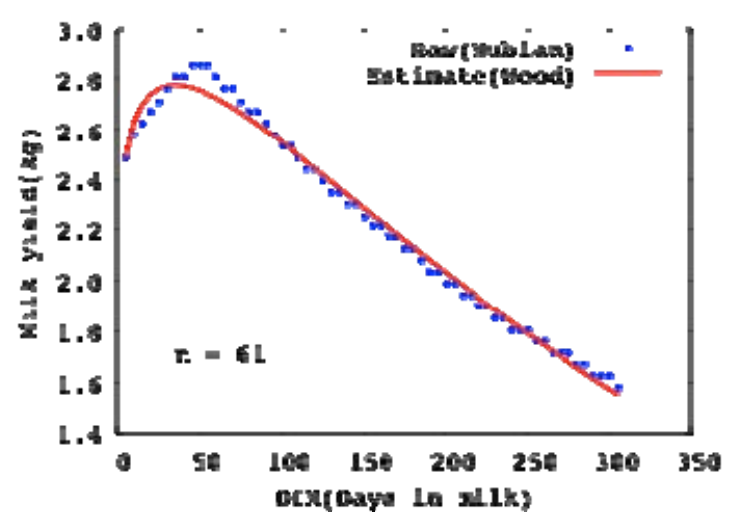

Figure 4. Transition of DIM and milk yield of goat

The prediction error was large in the day after delivery 0 to 100 . After 100 days, however, the deviation between the predicted value and the

Table 2. Parameter of lactation characteristic

\begin{tabular}{lccc}
\hline & actual & Prediction & error \\
\hline$t_{\max }$ (week) & 6.43 & 4.94 & -1.48 \\
$t_{\max }$ (day) & 45 & 35 & -10 \\
$y_{\max }(\mathrm{kg})$ & 2.85 & 2.78 & -0.07 \\
$s$ & - & 4.27 & - \\
$T M_{240}(\mathrm{~kg})$ & - & 561.83 & - \\
\hline \hline
\end{tabular}

Table 3. Error and the Residual Sum of Squares of Each Breed

\begin{tabular}{lcccc}
\hline \hline & $\begin{array}{c}\text { Error of } \mathbf{t}_{\text {max }} \\
\text { (week) }\end{array}$ & $\begin{array}{c}\text { Error of } \mathbf{t}_{\max } \\
\text { (day) }\end{array}$ & $\begin{array}{c}\text { Error of } \mathbf{y}_{\max } \\
\mathbf{( k g )}\end{array}$ & $\begin{array}{c}\text { Squares of } \\
\text { error in each } \\
\text { breed }\end{array}$ \\
\hline Nubian & -1.48 & -10 & -0.07 & 0.0996 \\
Alpine & 0.81 & 6 & -0.14 & 0.1932 \\
LaMancha & -0.25 & -2 & -0.06 & 0.0827 \\
Oberhasli & 0.21 & 1 & -0.02 & 0.1046 \\
Saanen & 1.3 & 9 & -0.03 & 0.0969 \\
Toggenburg & 0.81 & 6 & -0.05 & 0.0768 \\
\hline \hline
\end{tabular}


raw gets smaller. Error between the measured value and the parameters derived from Wood equation obtained by the program were described in Table 2.

As shown in the table above, there are slight difference between the actual result and predicted result. And Table 3 is shown the difference between actual data and parameters derived by Wood in various breed of goat.

\subsection{Calculation of nutrient requirement}

In this study, the calculation program was developed in order to determine the amount of each individual nutritional requirement. The development was based on NRC feeding standard [7]. Feeding standard is that shows the requirement of major nutrients in individual animals.

DM (Dry Matter): The dry matter is a measurement of the mass of feed when completely dried.

TDN (Total Digestible Nutrition): TDN is one of the evaluation indexes of feed, the amount of matter digestible for animals.

CP (Crude Protein): Proteins and other compounds including nitrogen, like an amino acid.

DP (Digestible Protein): Crude Protein that is digestible for animal.

VA (Vitamin A): Lack of vitamin A can affect reproduction, growth, and immune function.

VD (Vitamin D): Vitamin D plays an important role in the metabolism of calcium and phosphorus.

CA (Calcium): Calcium is involved in the maintenance of blood pH. Principal component of bone, nerve and muscle stimulation, and coagulation of the blood.

P (Phosphorus): Phosphorus is involved in the metabolism of fat and sugar, such as principal component of bone.

Among the NRC standard, only the standard that shows in goat was used in this study. The amount of nutrients requirements were calculated according to the body weight of animal, level of exercise, body weight gain, milk yield and milk fat percentage in lactating animal.

The program was written in following equation. And, the required amount of each nutrient was obtained.
$R=a M+b G+(c F+d)+e$.

$M=W^{0.75}$.

As stated above, R, G, M, F, Y, W are represented as the nutrition requirement of animal[g], dairy gain[g/day], metabolic body size[g], milk fat percentage[\%], milk yield[kg], and body weight of animal[kg], respectively. System development for selecting the feed that matches the nutritional requirement obtained in this way is currently underway.

\subsection{Breeding system}

Study for the development of systems for selecting the excellent breeding stock has been carried out, too. It is an important issue to identify the high advantage animal, such as high yield of lactation or performance of meat production. Breeding is the process that is selection of the animals that has high ability of genetic, to improve the average value of group. Breeding is to identify superior animals in order to improve the average group of animals.

In order to perform the breeding, it is required to accurately grasp the blood relationship between individual animal. Furthermore, it is required to analyze and integrate the information such as indicators of productivity values obtained from other systems. In this study, the Best Linear Unbiased Prediction (BLUP) method was used to develop the system. BLUP method is a way to predict the breeding value with no bias, by removing the influence of environment effect, such as difference of farmer or season. Breeding value is the sum of gene effects of a breeding animal as measured by the performance of its progeny. In this system, sire model BLUP method was used for the selection of male goat according to the record of progeny. As stated above, the algorithm of sire model BLUP methods was described.

It can be expressed as following equation to apply a statistical model to the observed values of animal, when one genetic trait was focused.

$y_{i}=\bar{y}+b+u+\delta$.

Here, $y_{i}, \bar{y}, b$, and $u$ shows the observed value, the average value of the group, the effect of the environment and the father. However, the effect of farther affected to the genetic kinship between fathers and heritability of focused genetic trait in practice. In this equation, that is omitted. Following equation 
was obtained to introduce the design matrix of each effect $\mathrm{X}$ and $\mathrm{Z}$.

$y=X b+Z u+e$

Here, $e$ is the residual vector. And following equation were obtained by multiplying $\mathrm{X}^{\mathrm{T}}$, $\mathrm{t}$ are transposed matrices of design matrices.

$X^{T} y=X^{T} X b+X^{T} Z s+X^{T} e$.

$Z^{T} y=Z^{T} X b+Z^{T} Z s+Z^{T} e$.

The following equation is obtained by matrix display of the above equations.

$\left[\begin{array}{cc}X^{T} X & X^{T} Z \\ Z^{T} X & Z^{T} Z\end{array}\right]\left[\begin{array}{l}\hat{b} \\ \hat{u}\end{array}\right]=\left[\begin{array}{l}X^{T} y \\ Z^{T} y\end{array}\right]$

Here, it is considered that omitted effect in equation (12), genetic kinship of father and heritability. Also, matrix A shows the genetic kinship of father and $\lambda$ shows heritability were introduced to above equation. Then, the following equation of mixed model is obtained.

$\left[\begin{array}{cc}X^{T} X & X^{T} Z \\ Z^{T} X & Z^{T} Z+\lambda A^{-1}\end{array}\right]\left[\begin{array}{l}\hat{b} \\ \hat{u}\end{array}\right]=\left[\begin{array}{c}X^{T} y \\ Z^{T} y\end{array}\right]$

Design matrix and observations were known data, also it can be calculated that the effect of father and environment, to introduce the effect of genetic kinship and heritability. The $\lambda$ is variance ratio, and it was obtained from heritability approximately that representing following equation. The heritability is contribution rate for each genetic trait.

$\lambda=\frac{\sigma_{e}^{2}}{\sigma_{S}^{2}}=\frac{4-h^{2}}{h^{2}}$

For example, the heritability of milk yield of goat is 0.55 , on the other hand, the heritability of milk fat percentage is 0.10 [8]. This shows that the effect of genetic in milk fat percentage is lower than milk yield.

The following sample matrix, showing the genetic kinship between fathers, can be prepared based on the following Table 4 and equation (18).

Table 4. Sample Matrix showing the blood relationship between three fathers

\begin{tabular}{c|ccc}
\hline \hline & Father A & Father B & Father C \\
\hline Father A & 1 & $\mathrm{a}^{* \mathrm{~b}}$ & $\mathrm{a}^{* \mathrm{c}}$ \\
Father B & $\mathrm{a}^{* \mathrm{~b}}$ & 1 & $\mathrm{~b}^{*} \mathrm{c}$ \\
Father C & $\mathrm{a}^{*} \mathrm{c}$ & $\mathrm{b}^{*} \mathrm{c}$ & 1 \\
\hline \hline
\end{tabular}

The $a * b$ is shown the value of genetic kinship between the fathers. These values are obtained by following equation. This equation is the numerator part of Wright equation, showing genetic relationship, as

$a b=\Sigma\left\{0.5^{n+n^{\prime}}\left(1+F_{A}\right)\right\}$

In the equation (18), $F_{A}$ is the inbreeding coefficient, and $n$ and n' are the number of generation, $\mathrm{X}$ to $\mathrm{A}$ or $\mathrm{C}$. If there is no genetic relationship, this matrix is shown in unit matrix.

\section{Discussion and Conclusions}

In this study, a next-generation information management system for animal production that is utilizing ICT, RFID, cloud systems, and mobile communication network have been proposed. Considerations of the challenges for the experimental operation of the system for dairy goat farmers are described below.

\subsection{System configuration and the price of the system}

In this newly developed system, inexpensive embedded devices and existing load cells were used. It is considered that, by the using these devices, an inexpensive system could be built. Important idea of animal production information management system that we propose is, when it comes to build or implement the systems for collecting information in the field of animal production. It is crucial to step back from the business model such like selling the systems to farmers in order to gain the selling profit from them. It is necessary to provide the system for free of charge in order to collect information in the cooperative relationship with farmers. It may also be considered that we promote the implementation of the systems to the farmers with financial consideration. The financial consideration may be paid to the farmers because farmers can be deemed as providers of the useful data in related with the animal production for pharmaceutical companies, feed manufacturing companies, etc. for its secondary usage of information. When the system is realized and operated in the considerable number of animal farmers, big data will be collected and stored in the database automatically.

Therefore, the second users of the information database will be able to retrieve data from the 
database for the purpose of their own (i.e. the research and development of their new feeding products and new veterinary drugs.) The usage of data may include, but not limited to, the demand forecast for feed consume and largescale clinical trial tests for newly developed veterinary drugs. The business model that we propose in this study is fully focused on getting the most of the revenue from the sales of the information. In order to have this business model being sustainable, the manufacturing cost for the hardware of the system should be lowered. In this study, the manufacturing cost of this system is about $\$ 7,800$, which are the costs that exclude the overhead costs involved in the development. If the rationalizations of the manufacturing process were achieved or considerable number of manufacturing order of the systems were taken, the manufacturing cost may be lowered significantly.

\subsection{Improvement of work flow and information literacy of workers}

As noted in the test results of this system operation, the disturbance to the measured value has occurred in relation to the farmers' working conditions and their awareness for the importance of the data integrity. It is assumed that the cause of the problem lies in the difference of the awareness of information between the management and production workers.

In most of the cases, the senior management is well aware of the importance of maintaining accurate measuring of the volume of milking in each individual animal. However, the workers may not have awareness for the accurate measurement.

It is necessary to focus not only on the improvement of the system itself, but also on the improvement of information literacy in the farm especially in Asian region. Providing the training in regards to the data accuracy may be effective to prevent the wrong and unintended usage of the system that we haven't noticed yet.

Recently, some studies have been done to improve the efficiency of energy utilization through the use of ICT in the agricultural sector [9]. Considered a number of benefits can be obtained by the use of ICT in the field of animal husbandry, will need to continue to promote, further research in this area.

\section{Acknowledgement}

This study was conducted with the assistance of the Ministry of Internal Affairs and Communications of Japan by SCOPE scheme. We were able to achieve full cooperation of Hagoromo Bokujo, Co. Ltd.

RFID tag and readers were provided by Surge MIYAWAKI Co. Ltd. We would like to presence the appreciation.

\section{REFERENCES}

1. VOULODIMS, A. S., A. B. PARTRIKIS, V. A. SIDERIDIS, A Complete Farm Management System based on Animal Identification using RFID Technology, Computers and Electronics in Agriculture Vol. 70, No. 2, 2010, pp. 380-388.

2. MITRA, K., D. BHATTACHARYYA, T.-H. KIM, Urban Computing and Information Management System Using Mobile Phones in Wireless Sensor Network, International Journal of Control and Automation, Vol. 3, No. 1, pp. 17-25.

3. WOOD, P. D. P., Algebraic of the Lactation Curve in Cattle, Nature No. 216, 1967, pp. 164-165.

4. UEHARA, S., Y. CHOUMEI, K. OISHI, Y. NAGURA, M. FUJITA, H. KUMAGAI, H. HIROOKA, Factors affecting the Lactation Curve Parameters of Japanese Saanen Goats, Japanese Journal of Animal Science, Vol. 78, 2007, pp. 139-145.

5. GIPSON, T. A., M. GROSSMAN, Lactation Curves in Dairy Goats: A Review, Small Ruminant Research, Vol. 3, No. 4, 1990 pp. 383-396.

6. UNITED STATES DEPARTMENT OF AGRICULTURE, http://aipl.arsusda.gov/reference/goat/lacc urv.htm 
7. SUBCOMMITTEE ON GOAT NUTRITION, COMMITTEE ON ANIMAL NUTRITION, BORD ON AGRICULTURE AND RENWABLE RESOURCES, COMMISSION ON NATURAL RESOURCES NATIONAL RESERCH COUNCLE, Nutrient Requirements of Goats: Angora, Dairy, and Meat Goats in Temperate and Tropical Countries, National Academy Press, 1981
8. ILOEJE, M. U., L. VLECK, Genetics of Goats, Journal of Dairy Science, Vol. 61, 1978, pp. 1521-1528.

9. LEE, H.-C., J.-H. HWANG, H. YOE, Energy Efficient MAC Protocol for Ubiquitous Agriculture, International Journal of Smart Home, Vol. 4, No. 3, pp. 15-26. 